\title{
Rethinking the Issue of Power Morcellation of Uterine Fibroids: Is Morcellation the Real Problem or Is this Another Symptom of Disparity in Healthcare Provision?
}

\author{
FUNLAYO ODEJINMI $^{1}$, MEHRNOOSH AREF-ADIB ${ }^{1}$, NATASHA LIOU $^{1}$, \\ MICHAIL SIDERIS ${ }^{2}$ and REBECCA MALLICK ${ }^{3}$ \\ ${ }^{1}$ Whipps Cross Hospital, Barts Health NHS Trust, London, U.K.; \\ ${ }^{2}$ Women's Health Research Unit, Queen Mary University of London, London, U.K.; \\ ${ }^{3}$ Princess Royal Hospital, Brighton and Sussex University Hospitals NHS Trust, Haywards Heath, U.K.
}

\begin{abstract}
Power morcellation remains one of the most significant developments in minimal access surgery over the past decade, allowing many more patients to benefit from the least invasive surgical route. However, its use is not without controversy, particularly with regards to the risks of an undiagnosed leiomyosarcoma. Increased media and, in particular, on-going social media coverage since events in 2014 have only served to intensify the debate, culminating in the Food and Drug Administration essentially 'banning' its use in the USA. Practice however continues to vary and this technique remains widely used in Europe and in particular the UK. The aim of this article was to review the development of power morcellation in gynaecology and the underlying risks, including that of undiagnosed leiomyosarcoma, as well as appraise the evolving literature on patient awareness and informed consent and the wider implications of morcellation restriction.
\end{abstract}

Power morcellation has contributed to the advancement of minimally invasive surgery (MIS), which in turn has improved outcomes in gynaecological surgery. Unfortunately, the introduction of new technologies does not always go hand-inhand with a rigorous evidence base and since 2014, there has been much heated debate and controversy surrounding

This article is freely accessible online.

Correspondence to: Rebecca Mallick, Princess Royal Hospital, Brighton and Sussex University Hospitals NHS Trust, Lewes Road, Haywards Heath, RH16 4EX, U.K. Tel: +44 7411617143, e-mail: rmallick@doctors.org.uk

Key Words: Laparoscopy, myomectomy, morcellation, leiomyosarcoma, review. morcellation. The aim of this article was to review the evolution of power morcellation in the management of fibroids and the risks of undiagnosed leiomyosarcoma (LMS), as well as the evolving literature on patient awareness and informed consent, the impact of social media, and the wider implications of morcellation restriction.

\section{The Evolution of Minimal Access Surgery and Morcellation}

Since the original publications by Semm in the 1980 s, laparoscopic myomectomy has evolved significantly and the decades have seen changes in the debates (1). In the 1990s, the primary considerations were which fibroids could and should be removed laparoscopically (2), but in the new millennium the size, number or location were less significant with numerous publications of series removing multiple fibroids up to $20 \mathrm{~cm}$ in size $(3,4)$.

The same evolutionary process occurred with laparoscopic hysterectomy since the first reported in 1989 (5). The eVALuate study highlighted that there were better outcomes with laparoscopic compared to open hysterectomy, but with a higher complication rate (6). This high complication rate was subsequently thought to be due to the relative laparoscopic inexperience of the 43 surgeons in the trial and the quality of equipment at the time (7). Other authors have since demonstrated that laparoscopic hysterectomy has a very low complication rate (8). The boundaries for both total and supracervical hysterectomy were advanced, supported by good safety data and positive long-term outcomes (9) and increasingly large uteri were removed laparoscopically using modified techniques (10-12).

The increasing complexity of these procedures have in part been enabled by the 'power morcellator'. Since the first 
mechanical morcellator was described by Semm (13) and the electrical morcellator was introduced in 1993, with subsequent approval by the U. S. Food and Drug Administration (FDA) in 1995; many other devices have since been brought to market and described in the literature (14). Initially all seemed well with power morcellation, however, it was noted that due to the cylindrical nature of the instrument with its rapidly rotating tip, there was an increased spread of the morcellated tissue pieces within the abdominal cavity and the potential risk of inadvertent spread of malignancy. Thus, as with the initial concerns regarding increased complications resulting from laparoscopic surgery in the early 1990s, would the power morcellator prove to be the Achilles heel in the further advancement of MIS? (15).

In 2014, Milad and Milad published a systemic review of morcellator complications and found only 55 had been reported over a 15-year period and were mainly related to surgical experience (16). The majority of complications were identified through the FDA database and not from published literature, highlighting possible under-reporting and publication bias. Although the report highlighted the mechanical trauma complications, it did not address the issues of the spread of benign diseases (iatrogenically disseminated leiomyomatosis, parasitic leiomyomas and iatrogenic adenomyosis) or the potential spread of 'inadvertently' present cancer such as sarcoma or LMS.

Disseminated leiomyomatosis is a rare disease first described in 1965 (17), with initial cases reported well before the advent of morcellation. In recent times, some cases have been reported following power morcellation with cellular structures being the same within the morcellated myoma and the peritoneal leiomyomatosis, highlighting the need for vigilance (18).

Parasitic fibroids have been reported since the early 1900s and it was initially hypothesised they resulted from the detachment of a pedunculated uterine fibroid and subsequent re-attachment and development of an independent blood supply (19). This previously rarely seen fibroid type became increasingly commonly found with the growing use of morcellation, with Ostrzenski reporting the first case following laparoscopic myomectomy in 1997 (20). This has been followed by numerous case reports and the incidence of parasitic myomas varies between prospectively and retrospectively collected data. A systemic review on behalf of the European Society of Gynaecological Endoscopy concluded the incidence of parasitic myoma following either hysterectomy or myomectomy to be $0.12-0.95 \%$, and 0.2 $1.25 \%$ after laparoscopic myomectomy (21). It has been hypothesised that iatrogenic fibroids after morcellation result from small fragments being inadvertently or otherwise left behind post procedure $(22,23)$. In a prospective study of 505 women undergoing an laparoscopic myomectomy, the incidence of parasitic myoma was found to be lower at $0.2 \%$
(3). Donnez et al., who prospectively followed-up women for 17-years following laparoscopic supracervical hysterectomy, found an incidence of iatrogenic adenomyosis of $0.56 \%$ (8).

\section{Leiomyosarcoma and the Evidence}

Uterine sarcomas constitute $2-7 \%$ of uterine tumours, of which LMS are the commonest type. The overall incidence remains low, however they are twice as common in Black women. The prognosis for the majority of women who have LMS is poor and dependent on tumour type and stage of disease $(24,25)$. With the use of power morcellation, there is a real risk of up-staging LMS (26), and reducing the survival rate when compared to women who undergo hysterectomy without morcellation (27). Another problem associated with power morcellation is the difficulty or delay in diagnosis of specimens when compared to those obtained intact by pathologists $(28,29)$.

In 2013 Jennifer Levitz reported in the Wall Street Journal the case of Amy Reed, an anaesthetist who underwent hysterectomy for fibroids and was 'inadvertently' found to have an LMS post-procedure, which was up-staged as a result of the use of power morcellation (30). This incident was followed by the development of multiple pressure and lobby groups, including a campaign by Reed's husband Hooman Noorchashm, and strong media involvement. The FDA, in 2014, subsequently issued a statement quantifying the risk of sarcoma in women who underwent hysterectomy/myomectomy at 1:352 and the risk of LMS at 1:498 (31). The FDA then advised that power morcellation was contraindicated in peri/post- menopausal women, essentially banning the product from use (32). There were many criticisms of the FDA's actions and the social implications and methodological flaws were summarised by Rosenbaum in the New England Medical Journal (33). The FDA erroneously lowered the denominator thus increasing the apparent risk and the quality of the mostly retrospective data was poor.

There was also the issue of the FDA focusing more on harm for the women who used the device, rather than the harm that could come to women who were deprived of its use, as open surgery carries more frequent higher risks than the rarer risk of an inadvertent LMS diagnosis following power morcellation. This was explored in a hypothetical model by Seidhoff and colleagues (34). They concluded that though there were more deaths after an LMS diagnosis following morcellation when compared to no morcellation, there were even more deaths when women underwent conventional open hysterectomy. The laparoscopic group also had lower risks of infection, thrombosis, blood transfusion, and incisional hernia.

How the emotive social debate influenced the FDA is unknown, but no matter how low the risks of using power morcellation are, for any family affected by LMS, the risk is 
understandably too high if it results in the loss of a loved one But, on balance, if devices are to be withdrawn from use, the risks and benefits need to be weighed up so that informed decisions can be made by both patient and clinicians.

On the issue of denominators used for determining risk, Pritts and colleagues in a meta-analysis of 133 studies determined the risk of LMS to be one per 2,000 procedures and when the meta-analysis was restricted to prospective studies the risk devised to one in 8,300 surgeries for uterine fibroids (35). When Pritts applied their statistical analysis to the results from the FDA, the risk was $8 \%$ lower, further emphasising the flaw in the methodology of the FDA report.

Three years following its initial statement, the FDA revised its analysis to 1:225-1:580 occult cancers in women after myomectomy/hysterectomy and 1:495-1:1,100 for those after LMS. The US Department of Health and Human Services updated the evidence provided by the Pritts study using the same methodology and found the prevalence rate of LMS to be 1:1,429; when only studies with reliable data were analysed with proven histology. the rate of LMS was less than one in 4,000 surgeries (36).

Since the FDA statements and guidance from British and European gynaecological societies and government agencies who advocate the continued use of morcellators (37-40), the social debate has been polarised into two main groups:

I: Those who lobby to completely ban the morcellator on the basis that there is no evidence to enable women to make informed consent.

II: Those trying to make a case for its continued use thus striving to improve the evidence base by:

a. Deciphering the true denominator and the true risk of LMS.

b. Evaluating the true impact of non-use of power morcellators.

c. Searching for alternatives to power morcellation.

\section{The Impact on Minimal Access Surgery Since 'Banning' of Morcellation}

In the USA since the 'banning' of power morcellation, there has been a decline in the number of minimal access procedures, with an increase in open surgery without an increase in complication rates at some institutions at the hands of well-trained gynaecologists (34). However, a subsequent study did demonstrate a decline in MIS and an increase in major non-transfusion complications and readmission rates (41).

\section{The True Incidence of Occult Cancer}

Large retrospective studies are now available looking into the risk of undiagnosed cancer in women who undergo surgery for presumed benign fibroids. Wright et al., in a retrospective analysis of women who underwent myomectomy from 496 centres in the USA, identified uterine cancer in one out of 528 women who underwent myomectomy without power morcellation and in one out of 1,073 who underwent power morcellation. The rate of any pathological finding of any cancer was $0.67 \%$ (42).

Skorstad and colleagues, in a national Norwegian retrospective study, reported the incidence of LMS at 0.86 in 100,000 women and $0.3 \%$ of women who had a hysterectomy (43). Another national study from the Netherlands found the overall incidence of LMS to be $0.25 \%$ or one in 1,400 women. The incidence of unexpected LMS was $0.12 \%$ or 1:865 (44). In a recent American population-based study of women undergoing hysterectomy, the incidence of unsuspected sarcoma was $0.13 \%$, whilst the incidence of undiagnosed sarcoma in women with fibroids was $0.35 \%$ for premenopausal women and $0.57 \%$ in post-menopausal women. The overall incidence of LMS was low, however, the incidence increased with increasing uterine weight: $0.03 \%$ among women with a uterine weight $<250 \mathrm{~g}$ versus $15.4 \%$ in those with with a uterine weight $\geq 2,000 \mathrm{~g} \mathrm{(45)}$.

\section{The Social Media: The Lobby Groups}

With the proliferation of social media platforms, medical practitioners, patients and the general public have access to published literature and topical issues affecting health care and its provision. This is coupled with tragic personal stories that can influence public opinion. One recent example is an emotive open letter written by Noorchashm to the UK Royal College of Obstetricians and Gynaecologists (RCOG), addressing the RCOG's draft patient information leaflet and the current use of morcellation in the UK, stating that informing patients of risks is not "informed consent", but may in fact be negligence (46). Whist any iatrogenic misfortune is unacceptable and every complication worth thorough investigation, it is sometimes difficult to disentangle fact from personal opinion and evidence-based medicine, as may be the case with LMS.

\section{Patient Knowledge and Awareness}

Current evidence of patient awareness, is provided in a survey of the American Association of Gynecologic Laparoscopists (AAGL) Advancing Minimally Invasive Gynecologic Surgery Worldwide and the American College of Obstetrician and Gynecologists Collaborative Ambulatory Research Network members, where $74.6 \%$ of practitioners believed that fewer than $50 \%$ of patients were aware of the FDA statement regarding morcellation (47).

Mowers et al. investigated the knowledge and perception of patients on the issue of morcellation (48). In an anonymous survey of 500 patients (80\% Caucasian) with a 
response rate of $79 \%$, only $8.3 \%$ of patients had heard of morcellation. Narrowing this down to those who were about to, or already had undergone a hysterectomy/myomectomy, awareness only increased to $12 \%$ for hysterectomy and was only $7 \%$ for myomectomy. Of the women asked, only $4 \%$ would choose open surgery over the minimal access approach even when aware of the risks of morcellation. Both studies demonstrate a relative lack of patient awareness of morcellation and the need for patient education.

\section{Reactions from Practising Gynaecologists}

How gynaecologists have reacted to the FDA statement varies from country to country. In the USA, where the impact of the statement was felt most, Desai performed an online survey of AAGL faculty members and although the response rate was only $29 \%, 61 \%$ had not encountered a patient with LMS in their practice, but the majority had been using open procedures since the statement (49). Nezhat et al., in an internet survey of members of the society of laparoendoscopic surgeons, found that $76 \%$ of participants performed laparotomy in fewer than $25 \%$ of their cases with most still favouring MIS techniques. However, those who believed that morcellation would upstage LMS if found, were more likely to use open procedures since the statement (50). In contrast, a recent survey of UK gynaecologists showed that on reviewing the evidence, they would continue to use power morcellation (51). In an Italian study, the respondents were more concerned about the medico-legal implications rather than the real risks of up-staging LMS (52).

\section{Improving the Diagnosis}

Historically LMS was thought to be exceptionally rare, restricted to women over 50 years of age, and more likely in those with a rapidly enlarging uterus. However, in 1994, Parker and colleagues investigated a cohort of 1,332 women and found a low incidence of LMS, which was particularly low in those who had rapidly enlarging uteri (53). This finding was also corroborated by Nagai et al., who concluded that women with benign disease were more likely to have rapid enlargement than those with sarcoma (54). Conversely in pre-menopausal women, fibroids that do not decrease in size after fibroid embolisation or with the use of gonadotropin-releasing hormone analogues should arouse suspicion of LMS and warrant further investigation (55). The triage of patients based on risk factors combined with investigation may help in the pre-operative assessment.

History. The risk of LMS is higher in Black women $(1: 25,000$ vs. 1:1400) (56). Age is also a risk factor, with the majority of cases of LMS occurring over the age of 60 years. Table I summarises potential risk factors.
Investigation. There are emerging investigations that might increase pre-operative diagnosis, however, limitations stem from the rarity of LMS. Blood tests, such as cancer antigen 125 (CA125) and lactose dehydrogenase (LDH), have been assessed, but have a poor positive predictive value (PPV). Using ultrasound alone, Bean and colleagues found that the sensitivity and specificity for diagnosis of uterine sarcoma was $85.7 \%$ and $99.5 \%$, respectively (57). Endometrial biopsy has a predictive value of $64-86 \%$ depending on infiltration of the endometrial cavity (58). Newer techniques such as diffusion-weighted imaging MRI are promising, being able to differentiate between benign and malignant myomas in $92.4 \%$ of cases (59).

Gotto and colleagues compared a combination of LDH, conventional MRI and MRI with contrast and found specificity, PPV, negative predictive value (NPV), and diagnostic accuracy were $93.1 \%, 52.6 \%, 100 \%$ and $93.1 \%$ with MRI alone; 93.8\%, 83.3\%, $100 \%$ and 95.2\% with dynamic MRI alone; and 100\%, 100\%, 100\%, 100\% with combined use of LDH and MRI, respectively (60).

Nagai and colleagues retrospectively analysed blood tests, imaging studies, and the history of 63 women who were thought to have uterine sarcomas and proposed the Preoperative Sarcoma Score (PRESS), which consists of 7 points: 1 for positive magnetic resonance imaging (MRI) findings and 2 points each for LDH over 279, age over 49 years and positive cytological findings. When the PRESS was interpreted as positive ( $\geq 3$ points), the diagnostic accuracy, PPV, NPV, sensitivity and specificity were $84.1 \%$, $63.2 \%, 93.2 \%, 0.800$ and 0.854 , respectively (54). Although a step in the right direction, $75 \%$ of patients in this study underwent 'unnecessary' surgery.

As with other cancer types, some advocate the use of preoperative tumour biopsy. Kawamura et al. assessed the safety and outcome of biopsies following abnormal MRI in 435 women and found sensitivity, specificity, PPV and NPV of $100 \%, 98.6 \%, 58 \%$, and $100.0 \%$ respectively (61). Compared to other solid tumour types, the uptake of biopsies for uterine sarcomas is also not popular due to the possibility of spillage of sarcoma cells.

As described above LMS can be challenging to diagnose pre-operatively and a collective approach encompassing features in the patient's history as well as further investigations are advised (62). This will aid informed patient consent and identify those in whom the minimal access approach may be best avoided. A proposed preoperative pathway is described in Figure 1.

\section{Alternatives to Power Morcellation}

Mechanical vs. power morcellation. Initial studies did not appear to show any outcome differences between mechanical and power morcellation in the dissemination of LMS, primarily because the type of morcellation was not always 
Table I. Risk factors for leiomyosarcoma.

\begin{tabular}{|c|c|}
\hline Risk factor & Comment \\
\hline $\begin{array}{l}\text { Black race } v s . \text { non-Black } \\
\text { Post menopausal status }\end{array}$ & Incidence: 1:1400 vs. 1:2500 \\
\hline Age & $\begin{array}{l}\text { Mean age at diagnosis: } 60 \text { years } \\
\text { Lowest risk in women }<35 \text { years; highest risk in women }>65 \text { years }\end{array}$ \\
\hline $\begin{array}{l}\text { History of retinoblastoma } \\
\text { Pelvic irradiation }\end{array}$ & Higher risk of sarcoma in general \\
\hline $\begin{array}{l}\text { History of tamoxifen use } \\
\text { Hereditary leiomyomatosis } \\
\text { Renal cell cancer syndrome }\end{array}$ & Use for more than 5 years \\
\hline
\end{tabular}

known $(63,64)$. In a more recent review of 715 women, the 5-year survival was $30 \%$ with power morcellation and $59 \%$ with manual morcellation, which was similar to the $60 \%$ where no morcellation was used. The comparison however did not reach clinical significance (65).

Posterior colpotomy. Posterior colpotomy has long been used for the retrieval of specimens vaginally. Bogani et al. compared 100 women who had laparoscopic myomectomy and found no difference in operating time or complications when vaginal extraction was compared with power morcellation (66), which was similar to the findings of Ghezi and colleagues (67). It could be argued, however, that with the advancement of MIS techniques, most women would not be suitable as they have larger and more numerous fibroids than those in the afore-mentioned studies (68).

In-bag morcellation. The most popular proposed alternative is in-bag morcellation. Vargas et al. compared outcomes of women who underwent open versus contained morcellation and the only difference was an increase in operating time (69). Some argue that myometrial spillage occurs during the process of myomectomy and that spillage of myometrial cells has been noted even after open myomectomy (70). Others suggest that thorough irrigation after the use of power morcellation will negate the need to use a bag (71) and even when bags are used, myometrial cells can still be found within the abdomen (72). Using the Health Failure Mode and Effects Analysis, potential weaknesses of the in-bag morcellation technique has been demonstrated, particularly with respect to the potential hazardous steps with morcellation, and these need to be rectified before it can be recommended for daily use outside clinical trials (73).

\section{Conclusion}

Our review supports the fact that although LMS is rare and the FDA figures may have exaggerated the problem, LMS may well be more common than previously thought and vigilance is crucial. Morcellation, not only up-stages LMS, but may also be responsible for parasitic fibroids and leiomyomatosis, which can be prevented by meticulous surgical techniques and potentially using contained morcellation. Even if a bag is used, the key should be copious irrigation to wash out any possible seeding and the routine use of contained morcellation needs further studies before widespread recommendation.

Since the onset of the debate, all efforts have been focused on collecting data on the prevalence and incidence of LMS following hysterectomy/myomectomy as if to maintain the status quo. Although the burden of fibroids on the individual woman and society is known, there are no good long-term outcome studies relating to the management of uterine fibroids including the issue of LMS. For other types of gynaecological cancer, although not as rare, when organised and centralised, there have been improvements in care and outcomes. Is a reason for the 'non-organisation' of fibroid and LMS management part of wider ethnic inequalities in healthcare provision as has already been highlighted in a number of published articles? (74). This view was summaried by Wingo in a recent editorial aptly titled "Black Uteri Matter", where one of the reasons for disparity was patient education and awareness (75). Though disparity is unlikely to be the whole story, care needs to be taken that this is not just another issue to be added to concerns on inequalities of healthcare provision for ethnic minorities.

Our review suggests that although most guidance from gynaecological societies following the FDA morcellation statement suggests provision of patient information leaflets and informed consent, these are not based on prospective evidence and there are no overt moves to improve patient education. In order to provide detailed evidence, prospective databasing for all fibroid treatment options, within the confines of robust data protection, may be the solution. In the USA, there is the COMPARE-UF database and in Canada the CAPTURE study $(76,77)$, and although a 


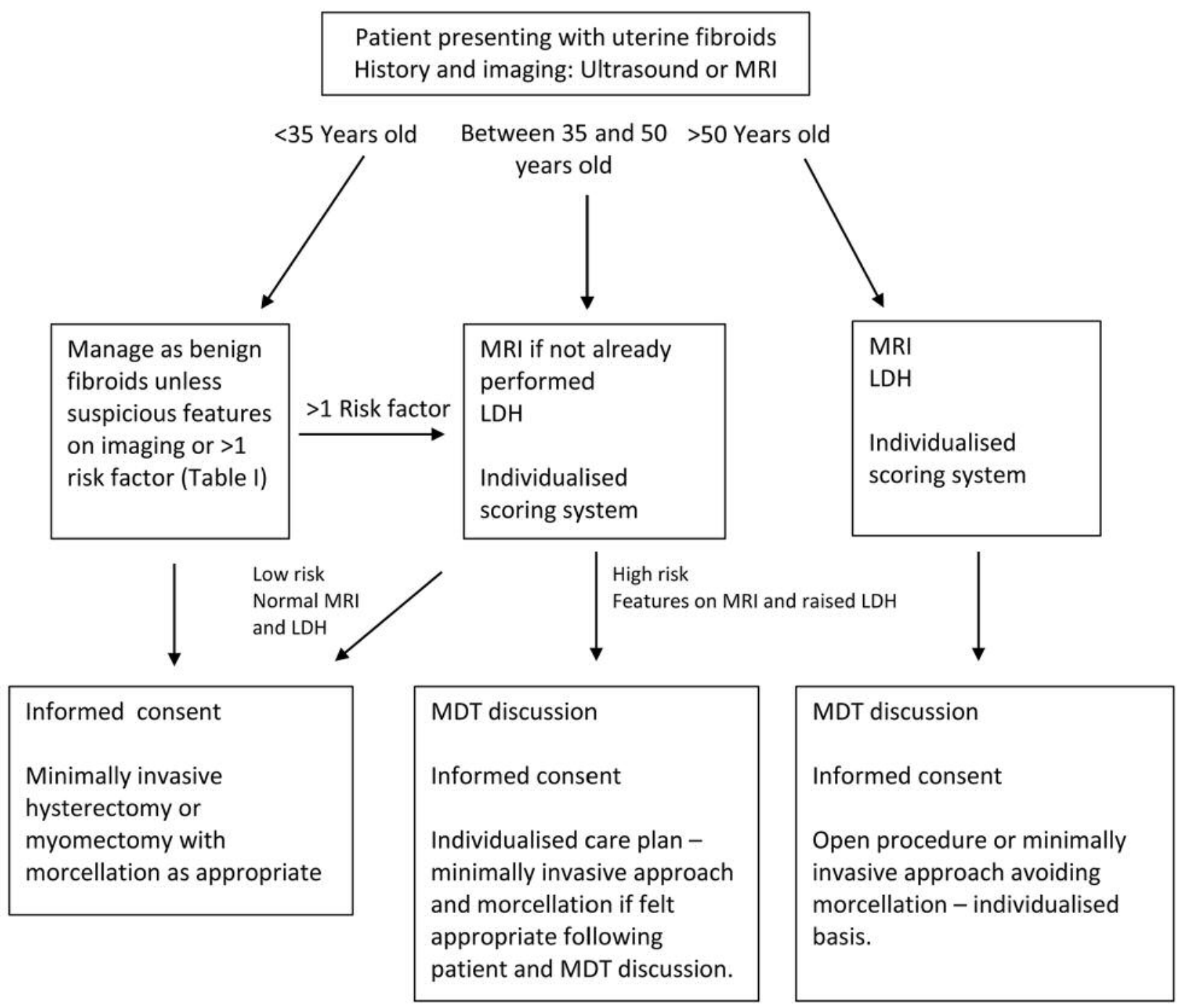

Figure 1. Proposed fibroid management pathway. LDH: Lactose dehydrogenase; MDT: multidisciplinary team; MRI: magnetic resonance imaging.

starting point, these databases do not address the issue of morcellation and LMS directly.

One approach to addressing this in order to improve the overall management of women with fibroids would be to ensure all healthcare providers mandatorily have databases to monitor outcomes of women who undergo any intervention for fibroids, as well as contributing to centralised LMS databases.

Information based on prospectively collected data will not only empower women to make decisions based on real-life data, it will also allow healthcare providers to provide information leaflets based on evidence rather than continuing to hypothesise. As informed consent should not be merely to protect doctors from litigation, but also for the improvement of the welfare of all patients who need up-to-date management of their fibroids.

\section{Conflicts of Interest}

None declared.

\section{Authors' Contributions}

FO conceived the idea. All Authors contributed to the preparation and editing of the article and reviewed the final draft.

\section{References}

1 Semm K and Mettler L: Technical progress in pelvic surgery via operative laparoscopy. Am J Obstet Gynecol 138(2): 121-127, 1980. PMID: 6448547. DOI: 10.1016/0002-9378(80)90021-6

2 Nezhat F, Seidman DS, Nezhat C and Nezhat CH: Laparoscopic myomectomy today: Why, when and for whom? Hum Reprod 
11(5): 933-934, 1996. PMID: 8671365. DOI: 10.1093/oxford journals.humrep.a019324

3 Sinha R, Hegde A, Mahajan C, Dubey N and Sundaram M: Laparoscopic myomectomy: Do size, number, and location of the myomas form limiting factors for laparoscopic myomectomy? J Minim Invasive Gynecol 15(3): 292-300, 2008. PMID: 18439500. DOI: 10.1016/j.jmig.2008.01.009

4 Mallick R and Odejinmi F: Pushing the boundaries of laparoscopic myomectomy: A comparative analysis of perioperative outcomes in 323 women undergoing laparoscopic myomectomy in a tertiary referral centre. Gynecol Surg 14(1): 22, 2017. PMID: 29200989. DOI: 10.1186/s10397-017-1025-1

5 Reich H, DeCaprio J and McGlynn F: Laparoscopic hysterectomy. J Gynecol Surg 5(2): 213-216, 1989. DOI: 10.1089/gyn.1989.5.213

6 Garry R, Fountain J, Mason S, Hawe J, Napp V, Abbott J, Clayton R, Phillips G, Whittaker M, Lilford R, Bridgman S and Brown J: The EVALUATE study: Two parallel randomised trials, one comparing laparoscopic with abdominal hysterectomy, the other comparing laparoscopic with vaginal hysterectomy. BMJ 328(7432): 129, 2004. PMID: 14711749. DOI: 10.1136/bmj. 37984.623889.F6

7 Garry R: Re-evaluating the eval uate study and the nice guidelines: A personal review. BJOG 123(11): 1796-1796, 2016. PMID: 27653329. DOI: 10.1111/1471-0528.13892

8 Donnez O, Jadoul P, Squifflet J and Donnez J: A series of 3190 laparoscopic hysterectomies for benign disease from 1990 to 2006: Evaluation of complications compared with vaginal and abdominal procedures. BJOG 116(4): 492-500, 2009. PMID: 19016683. DOI: 10.1111/j.1471-0528.2008.01966.x

9 Lieng M, Qvigstad E, Istre O, Langebrekke A and Ballard K: Long-term outcomes following laparoscopic supracervical hysterectomy. BJOG 115(13): 1605-1610, 2008. PMID: 18752588. DOI: 10.1111/j.1471-0528.2008.01854.x

10 Shahid A, Sankaran S and Odejinmi F: Laparoscopic subtotal hysterectomy for large uteri using modified five port technique. Arch Gynecol Obstet 283(1): 79-81, 2011. PMID: 20024572. DOI: $10.1007 / \mathrm{s} 00404-009-1322-7$

11 McGurk L, Oliver R and Odejinmi F: Laparoscopic supracervical hysterectomy for the larger uterus ( $>500 \mathrm{~g})$ : A case series and literature review. Arch Gynecol Obstet 295(2): 397-405, 2017. PMID 27848016. DOI: 10.1007/s00404-016-4237-0

12 Uccella S, Cromi A, Serati M, Casarin J, Sturla D and Ghezzi F: Laparoscopic hysterectomy in case of uteri weighing $\geq 1$ kilogram: A series of 71 cases and review of the literature. J Minim Invasive Gynecol 21(3): 460-465, 2014. PMID: 24012921. DOI: $10.1016 /$ j.jmig.2013.08.706

$13 \mathrm{Semm}$ K: Morcellement and suturing using pelviscopy - not a problem any more. Geburtshilfe und Frauenheilkunde 51(10): 843-846, 1991. PMID: 1837003. DOI: 10.1055/s-2008-1026221

14 Driessen SR, Arkenbout EA, Thurkow AL and Jansen FW: Electromechanical morcellators in minimally invasive gynecologic surgery: An update. J Minim Invasive Gynecol 21(3): 377-383, 2014. PMID: 24462590. DOI: 10.1016/j.jmig. 2013.12.121

15 Garry R: Laparoscopic morcellation: An acceptable risk or an Achilles heel? BJOG 122(4): 458-460, 2015. PMID: 25236787. DOI: $10.1111 / 1471-0528.13045$

16 Milad MP and Milad EA: Laparoscopic morcellator-related complications. J Minim Invasive Gynecol 21(3): 486-491, 2014. PMID: 24333632. DOI: 10.1016/j.jmig.2013.12.003
17 Taubert HD, Wissner SE and Haskins AL: Leiomyomatosis peritonealis disseminata; an unusual complication of genital leiomyomata. Obstet Gynecol 25(25): 561-574, 1965. PMID: 14268048.

18 Ordulu Z, Dal Cin P, Chong WW, Choy KW, Lee C, Muto MG, Quade BJ and Morton CC: Disseminated peritoneal leiomyomatosis after laparoscopic supracervical hysterectomy with characteristic molecular cytogenetic findings of uterine leiomyoma. Genes Chromosomes Cancer 49(12): 1152-1160, 2010. PMID: 20842731. DOI: $10.1002 / \mathrm{gcc} .20824$

19 Kelly HA and Cullen TS: Myoma of the Uterus. Saunders WB: Philladelphia PA, 1909.

20 Ostrzenski A: Uterine leiomyoma particle growing in an abdominal-wall incision after laparoscopic retrieval. Obstet Gynecol 89(5 Pt 2): 853-854, 1997. PMID: 9166349.

21 Van der Meulen JF, Pijnenborg JM, Boomsma CM, Verberg MF, Geomini PM and Bongers MY: Parasitic myoma after laparoscopic morcellation: A systematic review of the literature. BJOG 123(1): 69-75, 2016. PMID: 26234998. DOI: 10.1111/ 1471-0528.13541

22 Nezhat $\mathrm{C}$ and Kho K: Iatrogenic myomas: New class of myomas? J Minim Invasive Gynecol 17(5): 544-550, 2010. PMID: 20580324. DOI: 10.1016/j.jmig.2010.04.004

23 Hill DJ, Maher PJ and Wood EC: Lost surgical specimens. J Am Assoc Gynecol Laparosc 4(2): 277-279, 1997. PMID: 9050742.

24 Odejinmi F, Agarwal N, Maclaran K and Oliver R: Should we abandon all conservative treatments for uterine fibroids? The problem with leiomyosarcomas. Women's Health 11(2): 151159, 2015. PMID: 25776289. DOI: $10.2217 /$ whe.14.71

25 Hensley ML, Enserro D , Hatcher H, Ottevanger PB, Krarup Hanser A, Jean-Yves B, Cyril F, Katherine MM, Shashikant BL, Jayanthi SL, Krishnansu ST, Premal HT, Oliver Z, David MOM, Katina R and David SM: Adjuvant gemcitabine plus docetaxel followed by doxorubicin versus observation for high-grade uterine leiomyosarcoma: A phase III NRG Oncology/Gynecologic Oncology Group study. J Clin Oncol 36(33): 3324-3330, 2018. PMID: 30289732. DOI: 10.1200/JCO.18.00454

26 Park JY, Park SK, Kim DY, Kim JH, Kim YM, Kim YT and Nam JH: The impact of tumor morcellation during surgery on the prognosis of patients with apparently early uterine leiomyosarcoma. Gynecol Oncol 122(2): 255-259, 2011. PMID: 21565389. DOI: $10.1016 /$ j.ygyno.2011.04.021

27 Bretthauer M, Goderstad JM, Loberg M, Emilsson L, Ye W, Adami HO and Kalager M: Uterine morcellation and survival in uterine sarcomas. Eur J Cancer 101: 62-68, 2018. PMID: 30025231. DOI: 10.1016/j.ejca.2018.06.007

28 Rivard C, Salhadar A and Kenton K: New challenges in detecting, grading, and staging endometrial cancer after uterine morcellation. J Minim Invasive Gynecol 19(3): 313-316, 2012. PMID: 22417903. DOI: 10.1016/j.jmig.2011.12.019

29 Anupama R, Ahmad SZ, Kuriakose S, Vijaykumar DK, Pavithran K and Seethalekshmy NV: Disseminated peritoneal leiomyosarcomas after laparoscopic "myomectomy" and morcellation. J Minim Invasive Gynecol 18(3): 386-389, 2011. PMID: 21545964. DOI: 10.1016/j.jmig.2011.01.014

30 Levitz J: Fibroid Surgery Puts Doctor Fighting Cancer Diagnosis in Spotlight. Wall Street Journal, 2013. Available at: https:// www.wsj.com/articles/fibroid-surgery-puts-doctor-fightingcancer-diagnosis-in-spotlight-1387457121 (Accessed June 28, 2019) 
31 FDA: Laparoscopic uterine power morcellation in hysterectomy and myomectomy: FDA Safety Communication, 2014. Available at: https://www.chartrrg.com/wp-content/uploads/2014/07/FDAWarning.pdf (Accessed June 28, 2019)

32 FDA: Updated laparoscopic uterine power morcellation in hysterectomy and myomectomy: FDA Safety Communication, 2014. Available at: https://wayback.archive-it.org/7993/ 20170404182209/https://www.fda.gov/MedicalDevices/Safety/Al ertsandNotices/ucm424443.htm (Accessed June 28, 2019)

33 Rosenbaum L: N-of-1 policymaking-tragedy, trade-offs and the demise of morcellation. N Engl J Med 374(10): 986-990, 2016. PMID: 26962735. DOI: 10.1056/NEJMms 1516161

34 Siedhoff MT, Wheeler SB, Rutstein SE, Geller EJ, Doll KM, Wu JM and Clarke-Pearson DL: Laparoscopic hysterectomy with morcellation vs .abdominal hysterectomy for presumed fibroid tumors in premenopausal women: A decision analysis. Am J Obstet Gynecol 212(5): 591 e591-598, 2015. PMID: 25817518. DOI: 10.1016/j.ajog.2015.03.006

35 Pritts EA, Vanness DJ, Berek JS, Parker W, Feinberg R, Feinberg J and Olive DL: The prevalence of occult leiomyosarcoma at surgery for presumed uterine fibroids: A meta-analysis. Gynecol Surg 12(3): 165-177, 2015. PMID: 26283890. DOI: 10.1007/s10397-015-08944

36 US Department of Health and Human Services Agency for Healthcare Research and Quality. Management of Uterine Fibroids. 2017 Available at: https://effectivehealthcare.ahrq.gov/topics/ uterine-fibroids/research-2017 (Accessed June 28, 2019)

37 AAGL practice report: Morcellation during uterine tissue extraction. J Minim Invasive Gynecol 21(4): 517-530, 2014. PMID: 24865630. DOI: $10.1016 /$ j.jmig.2014.05.010

38 Goff BA: SGO not soft on morcellation: Risks and benefits must be weighed. Lancet Oncol 15(4): e148-e2045, 2014. PMID: 24694631. DOI: 10.1016/S1470-2045(14)70075-0

39 ACOG: ACOG statement on power morcellation, 2014. Available at: https://www.acog.org/About-ACOG/News-Room/Statements/ 2014/ACOG-Statement-on-Power-Morcellation? (Accessed June 28, 2019)

40 BSGE: BSGE statement of power morcellation, 2014. Available at: https://www.bsge.org.uk/news/bsge-statement-power-morcellation/ (Accessed June 28, 2019)

41 Harris JA, Swenson CW, Uppal S, Kamdar N, Mahnert N, AsSanie S and Morgan DM: Practice patterns and postoperative complications before and after us food and drug administration safety communication on power morcellation. Am J Obstet Gynecol 214(1): 98 e91-98 e13, 2016. PMID: 26314519. DOI: 10.1016/j.ajog.2015.08.047

42 Wright JD, Tergas AI, Cui R, Burke WM, Hou JY, Ananth CV, Chen L, Richards C, Neugut AI and Hershman DL: Use of electric power morcellation and prevalence of underlying cancer in women who undergo myomectomy. JAMA Oncol 1(1): 6977, 2015. PMID: 26182307. DOI: 10.1001/jamaoncol.2014.206

43 Skorstad M, Kent A and Lieng M: Uterine leiomyosarcoma incidence, treatment, and the impact of morcellation. A nationwide cohort study. Acta Obstet Gynecol Scand 95(9): 984990, 2016. PMID: 27223683. DOI: 10.1111/aogs.12930

44 van den Haak L, de Kroon CD, Warmerdam MI, Siebers AG, Rhemrev JP, Nieboer TE and Jansen FW: Incidence and groups at risk for unexpected uterine leiomyosarcoma: A Dutch nationwide cohort study. Arch Gynecol Obstet 299(1): 159-165, 2019. PMID: 30498966. DOI: 10.1007/s00404-018-4949-4
45 Multinu F, Casarin J, Tortorella L, Huang Y, Weaver A, Angioni S, Melis GB, Mariani A, Stewart EA and Laughlin-Tommaso SK: Incidence of sarcoma in patients undergoing hysterectomy for benign indications: A population-based study. Am J Obstet Gynecol 220(2): 179 e171-179 e110, 2019. PMID: 30447212. DOI: $10.1016 /$ j.ajog.2018.11.1086

46 Noorchashm N: An Open Critique to the Royal College of Obstericians and Gynaecologists: On Laparoscopic Morcellation, 2018. Available at: https://medium.com/@noorchashm/an-opencritique-to-the-royal-college-of-obstetrics-and-gynaecologistson-laparoscopic-50d54902b7ae (Accessed June 28, 2019)

47 Lum DA, Sokol ER, Berek JS, Schulkin J, Chen L, McElwain CA and Wright JD: Impact of the 2014 food and drug administration warnings against power morcellation. J Minim Invasive Gynecol 23(4): 548-556, 2016. PMID: 26827905. DOI: 10.1016/j.jmig.2016.01.019

48 Mowers EL, Lim CS, Skinner B, Mahnert N, Till SR and As-Sanie S: Patients' knowledge and perceptions of morcellation. JSLS 21(3), 2017. PMID: 28694681. DOI: 10.4293/JSLS.2017.00009

49 Desai VB, Guo XM and Xu X: Alterations in surgical technique after fda statement on power morcellation. Am J Obstet Gynecol 212(5): 685-687, 2015. PMID: 25735888. DOI: 10.1016/j.ajog. 2015.02.027

50 Nezhat F, Apostol R, Greene AD and Pilkinton ML: To morcellate or not to morcellate: A cross-sectional survey of gynecologic surgeons. JSLS 21(1), 2017. PMID: 28144125. DOI: $10.4293 /$ JSLS.2016.00092

51 Sankaran S, Brown A, Kent A and Odejinmi F: Laparoscopic specimen retrieval and attitudes towards morcellation: A questionnaire survey of gynaecology consultants in the United Kingdom. J Obstet Gynaecol 39(3): 345-348, 2019. PMID: 30422734. DOI: $10.1080 / 01443615.2018 .1493096$

52 Mandato VD, Torricelli F, Pirillo D, Aguzzoli L, Abrate M, Palomba S and La Sala GB: Impact of the food and drug administration safety communication on the use of power morcellator in daily clinical practice: An Italian survey. J Minim Invasive Gynecol 23(2): 206-214, 2016. PMID: 26454195. DOI: 10.1016/j.jmig.2015.09.021

53 Parker WH, Fu YS and Berek JS: Uterine sarcoma in patients operated on for presumed leiomyoma and rapidly growing leiomyoma. Obstet Gynecol 83(3): 414-418, 1994. PMID: 8127535.

54 Nagai T, Takai Y, Akahori T, Ishida H, Hanaoka T, Uotani T, Sato S, Matsunaga S, Baba K and Seki H: Novel uterine sarcoma preoperative diagnosis score predicts the need for surgery in patients presenting with a uterine mass. Springerplus 3(1): 678, 2014. PMID: 26405640. DOI: 10.1186/2193-1801-3-678

55 Papadia A, Salom EM, Fulcheri E and Ragni N: Uterine sarcoma occurring in a premenopausal patient after uterine artery embolization: A case report and review of the literature. Gynecol Oncol 104(1): 260-263, 2007. PMID: 17083970. DOI: 10.1016/ j.ygyno.2006.08.051

56 Brooks SE, Zhan M, Cote T and Baquet CR: Surveillance, epidemiology, and end results analysis of 2677 cases of uterine sarcoma 1989-1999. Gynecol Oncol 93(1): 204-208, 2004. PMID: 15047237. DOI: 10.1016/j.ygyno.2003.12.029

57 Bean E, Foo X, Wong M, Saridogan E and Jurkovic D: The efficacy of preoperative ultrasound in detecting uterine sarcoma prior to myomectomy. Ultrasound Obstet Gynecol 52(S1): 18, 2018. DOI: $10.1002 /$ uog. 19258 
58 Bansal N, Herzog TJ, Burke W, Cohen CJ and Wright JD: The utility of preoperative endometrial sampling for the detection of uterine sarcomas. Gynecol Oncol 110(1): 43-48, 2008. PMID: 18445505. DOI: 10.1016/j.ygyno.2008.02.026

59 Tamai K, Koyama T, Saga T, Morisawa N, Fujimoto K, Mikami $\mathrm{Y}$ and Togashi $\mathrm{K}$ : The utility of diffusion-weighted $\mathrm{mr}$ imaging for differentiating uterine sarcomas from benign leiomyomas. Eur Radiol 18(4): 723-730, 2008. PMID: 17929022. DOI: 10.1007/s00330-007-0787-7

60 Goto A, Takeuchi S, Sugimura K and Maruo T: Usefulness of gd-dtpa contrast-enhanced dynamic mri and serum determination of LDH and its isozymes in the differential diagnosis of leiomyosarcoma from degenerated leiomyoma of the uterus. Int J Gynecol Cancer 12(4): 354-361, 2002. PMID: 12144683.

61 Kawamura N, Ichimura T, Ito F, Shibata S, Takahashi K, Tsujimura A, Ishiko O, Haba T, Wakasa $\mathrm{K}$ and Ogita $\mathrm{S}$ : Transcervical needle biopsy for the differential diagnosis between uterine sarcoma and leiomyoma. Cancer 94(6): 17131720, 2002. PMID: 11920533. DOI: $10.1002 /$ cncr.10382

62 Sizzi O, Manganaro L, Rossetti A, Saldari M, Florio G, Loddo A, Zurawin R, van Herendael B and Djokovic D: Assessing the risk of laparoscopic morcellation of occult uterine sarcomas during hysterectomy and myomectomy: Literature review and the ISGE recommendations. Eur J Obstet Gynecol Reprod Biol 220: 30-38, 2018. PMID: 29149644. DOI: 10.1016/j.ejogrb. 2017.10.030

63 Morice P, Rodriguez A, Rey A, Pautier P, Atallah D, Genestie C, Pomel C, Lhomme C, Haie-Meder C, Duvillard P and Castaigne D: Prognostic value of initial surgical procedure for patients with uterine sarcoma: Analysis of 123 patients. Eur J Gynaecol Oncol 24(3-4): 237-240, 2003. PMID: 12807231.

64 Singh SS, Scott S, Bougie O, Leyland N, Committee SCP-G, Leyland N, Wolfman W, Allaire C, Awadalla A, Bullen A, Burnett M, Goldstein S, Lemyre M, Marcoux V, Potestio F, Rittenberg D, Singh SS, Yeung G, Committee GOCE, Hoskins P, Miller D, Gotlieb W, Bernardini M and Hopkins L: Technical update on tissue morcellation during gynaecologic surgery: Its uses, complications, and risks of unsuspected malignancy. J Obstet Gynaecol Can 37(1): 68-81, 2015. PMID: 25764040

65 Hartmann KE, Fonnesbeck C, Surawicz T, Krishnaswami S, Andrews JC, Wilson JE, Velez-Edwards D, Kugley S and Sathe NA: Management of uterine fibroids. Comparative effectiveness review no. 195. Rockville (MD): Agency for healthcare research and quality, 2017.

66 Bogani G, Uccella S, Cromi A, Serati M, Casarin J, Sturla D and Ghezzi F: Electric motorized morcellator versus transvaginal extraction for myoma retrieval after laparoscopic myomectomy: A propensity-matched analysis. J Minim Invasive Gynecol 21(5): 928-934, 2014. PMID: 24780382. DOI: 10.1016/ j.jmig.2014.04.012

67 Ghezzi F, Casarin J, De Francesco G, Puggina P, Uccella S, Serati $\mathrm{M}$ and Cromi A: Transvaginal contained tissue extraction after laparoscopic myomectomy: A cohort study. BJOG 125(3): 367-373, 2018. PMID: 28467660. DOI: 10.1111/1471-0528. 14720
68 Miller CE: Is transvaginal contained tissue extraction for everyone? BJOG 125(3): 374, 2018. PMID: 28636771. DOI: 10.1111/1471-0528.14796

69 Vargas MV, Moawad GN, Sievers C, Opoku-Anane J, Marfori CQ, Tyan P and Robinson JK: Feasibility, safety, and prediction of complications for minimally invasive myomectomy in women with large and numerous myomata. J Minim Invasive Gynecol 24(2): 315-322, 2017. PMID: 27939896. DOI: 10.1016/j.jmig.2016. 11.014

70 Sandberg EM, van den Haak L, Bosse T and Jansen FW: Disseminated leiomyoma cells can be identified following conventional myomectomy. BJOG 123(13): 2183-2187, 2016. PMID: 27533508. DOI: 10.1111/1471-0528.14265

71 Sandberg EM, Cohen SL, Jansen FW and Einarsson JI: Analysis of risk factors for intraoperative conversion of laparoscopic myomectomy. J Minim Invasive Gynecol 23(3): 352-357, 2016. PMID: 26546180. DOI: 10.1016/j.jmig.2015.10.017

72 Takeda A, Tsuge S, Shibata M, Shinone S, Nakamura H and Watanabe K: Identification of leiomyoma cell sheets in peritoneal washings retrieved by an intraoperative red blood cell salvage device during laparoscopic-assisted myomectomy with in-bag manual tissue extraction: A pilot study. J Minim Invasive Gynecol 25(7): 1266-1273, 2018. PMID: 29631012. DOI: 10.1016/j.jmig.2018.03.026

73 van den Haak L, van der Eijk AC, Sandberg EM, Frank G, Ansink K, Pelger RCM, de Kroon CD and Jansen FW: Towards spill-free in-bag morcellation: A health failure mode and effects analysis. Surg Endosc 32(10): 4357-4362, 2018. PMID: 29987 561. DOI: $10.1007 / \mathrm{s} 00464-018-6284-\mathrm{z}$

74 Odejinmi F, Aref-Adib M and Mallick R: Association of patient race with surgical practice and perioperative morbidity after myomectomy. Obstet Gynecol 132(4): 1066-1067, 2018. PMID: 30247348. DOI: 10.1097/AOG.0000000000002906

75 Wingo SN: Black uteri matter. Obstet Gynecol 133(1): 4-5, 2019. PMID 30531579. DOI: 10.1097/AOG.0000000000003035

76 Stewart EA, Lytle BL, Thomas L, Wegienka GR, Jacoby V, Diamond MP, Nicholson WK, Anchan RM, Venable S, Wallace K, Marsh EE, Maxwell GL, Borah BJ, Catherino WH and Myers ER: The comparing options for management: Patient-centered results for uterine fibroids (COMPARE-UF) registry: Rationale and design. Am J Obstet Gynecol 219(1): 95 e91-95 e10, 2018. PMID: 29750955. DOI: 10.1016/j.ajog.2018.05.004

77 Bedaiwy MA, Janiszewski P, Singh SS, CAPTURE Steering Committee: A patient registry for the management of uterine fibroids in canada: Protocol for a multicenter, prospective, noninterventional study. JMIR Res Protoc 7(11): e10926, 2018. PMID: 30459144. DOI: 10.2196/10926
Received May 14, 2019

Revised June 24, 2019

Accepted July 4, 2019 